\title{
Enzyme Kinetics via Open Circuit Potentiometry
}

Lettie A. Smith ${ }^{\mathrm{a},}$, , Matthew W. Glasscott ${ }^{\mathrm{a},}$, Kathryn J. Vannoy ${ }^{\mathrm{a}}$, and Jeffrey E. Dick ${ }^{\mathrm{a}, \mathrm{b} *}$

${ }^{a}$ Department of Chemistry, The University of North Carolina at Chapel Hill, Chapel Hill, NC 27599, USA

${ }^{b}$ Lineberger Comprehensive Cancer Center, School of Medicine, The University of North Carolina at Chapel Hill, Chapel Hill, NC 27599, USA

$\S$ These authors contributed equally to this work.

*To whom correspondence should be addressed: e-mail: jedick@email.unc.edu Telephone: +1-919966-5229

Table of Contents Page

Bulk Electrolysis of Ferrocenemethanol (Figure S1) S-2

Cyclic Voltammograms of Different Mediators (Figure S2)

Potential Transients as a Function of Glucose Concentration (Figure S3)

S-4

Example Linear Region from an OCP Transient (Figure S4)

S-5

Mediator Structures (Figure S5)

S-6

Potential Transients under Air for 75 mM Glucose (Figure S6) 


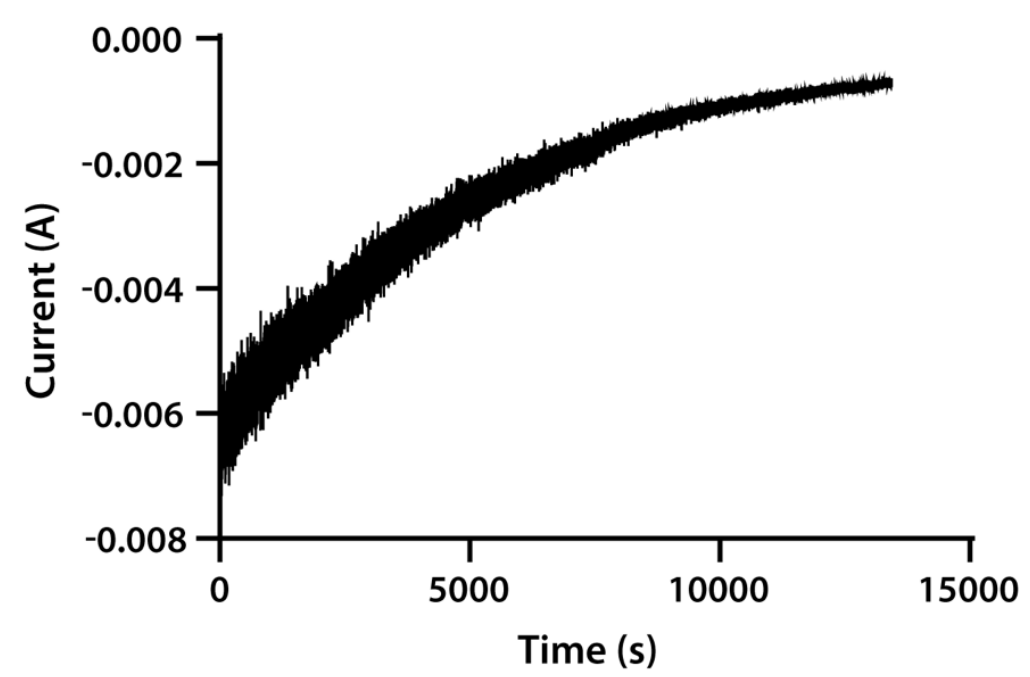

Fig S1. Bulk Electrolysis of Ferrocenemethanol to Produce Ferrocenium Methanol. Inital bulk electrolysis solution contained $5 \mathrm{mM} \mathrm{FcMeOH}$ in $1 \mathrm{X}$ PBS. A high surface area Pt coil working, glassy carbon rod counter, and $\mathrm{Ag} / \mathrm{AgCl}$ reference were used. The bulk electrolysis was held at $0.5 \mathrm{~V}$. 
A

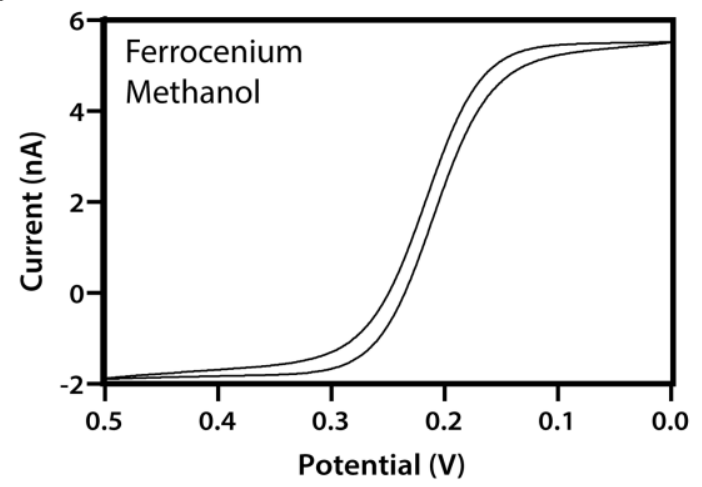

B

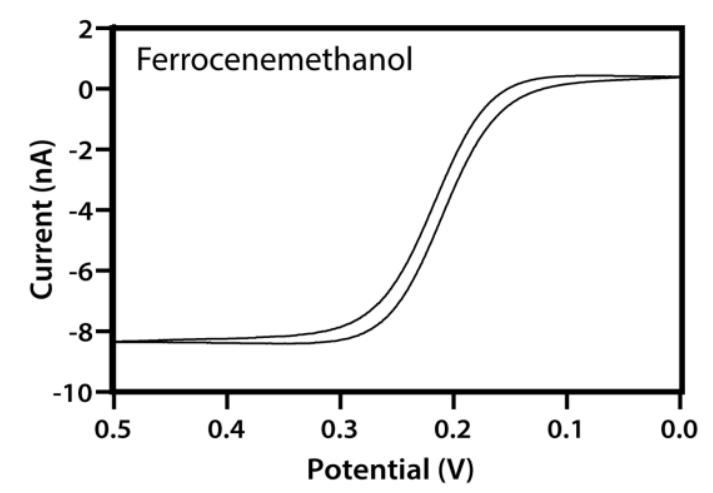

C

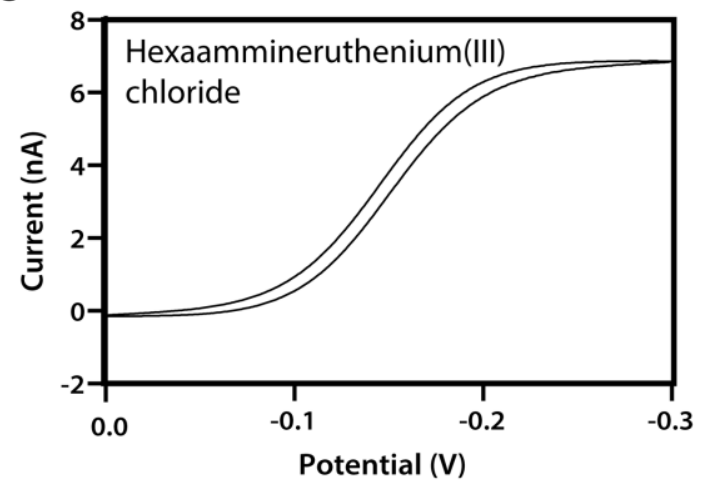

D

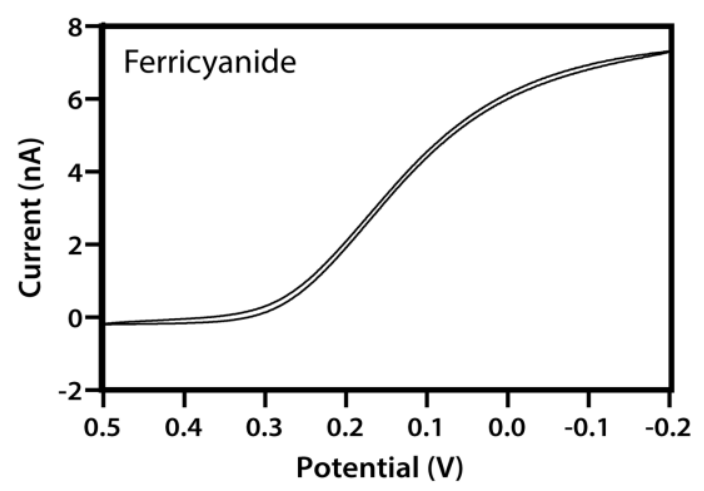

Fig S2. Cyclic Voltammograms of Different Mediators (A) Cyclic voltammogram of ferrocenium methanol. The CV was carried out on a gold microelectrode $(r=6.25 \mu \mathrm{m})$ with a glassy carbon rod counter electrode and a $\mathrm{Ag} / \mathrm{AgCl}$ reference electrode using a salt bridge. (B) Cyclic voltammogram of ferrocenemethanol. The CV was carried out on a gold microelectrode $(r=6.25 \mu \mathrm{m})$ with a glassy carbon rod counter electrode and a $\mathrm{Ag} / \mathrm{AgCl}$ reference electrode using a salt bridge. Ferrocenemethanol is included here because it was used in combination with ferrocenium methanol as a mediator to create the calibration curves in Figure 4B and 4D. (C) Cyclic voltammogram of hexaammineruthenium(III) chloride. The $\mathrm{CV}$ was carried out using a Pt UME $(r=5 \mu \mathrm{m})$ with a graphite rod counter electrode and a $\mathrm{Ag} / \mathrm{AgCl}$ reference. Prior to conducting the $\mathrm{CV}$, the solution was degassed for 15 minutes using $\mathrm{N}_{2}$ gas. (D) Cyclic voltammogram of ferricyanide. The CV was carried out using a gold microelectrode $(r$ $=6.25 \mu \mathrm{m}$ ) with a glassy carbon rod counter and a $\mathrm{Ag} / \mathrm{AgCl}$ reference. Prior to conducting the $\mathrm{CV}$, the solution was degassed for 15 minutes using $\mathrm{N}_{2}$ gas. The scan rate for all CVs was $0.05 \mathrm{~V} / \mathrm{s}$. 
A

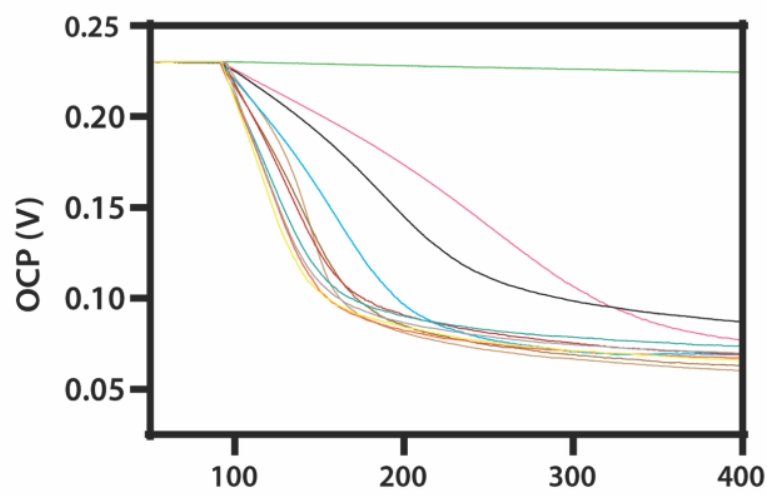

Time (s)

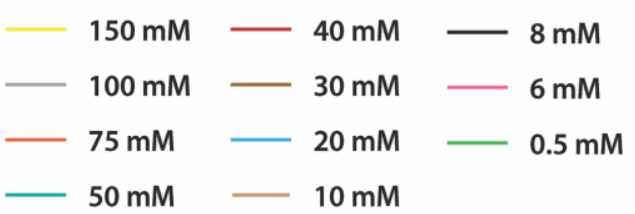

B

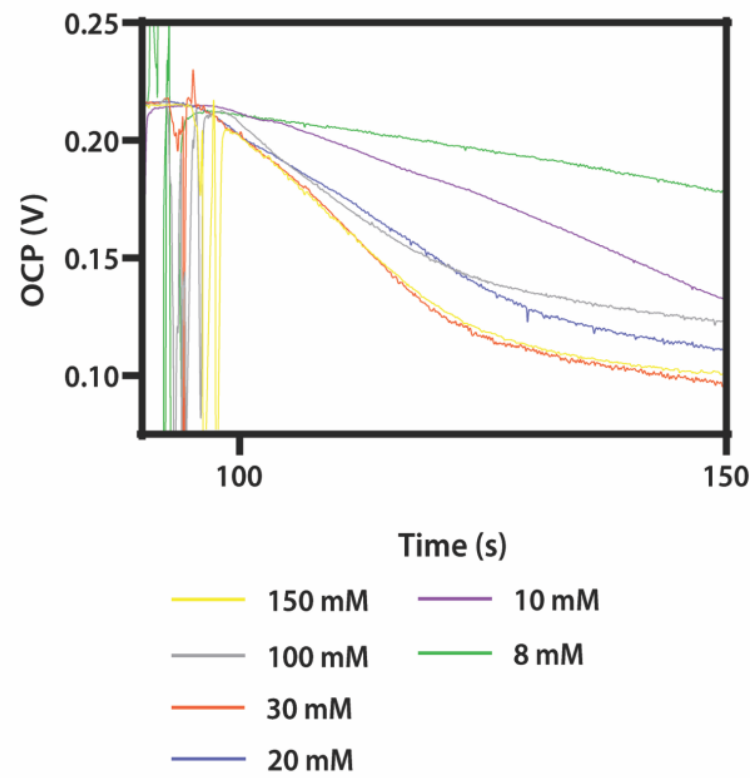

Fig S3. Potential Transients as a Function of Glucose Concentration (A) Potential transients on macroelectrodes as a function of glucose concentrations $(0.5 \mathrm{mM}$ to $150 \mathrm{mM})$. (B) Potential transients on microelectrodes as a function of glucose concentration $(8 \mathrm{mM}$ to $150 \mathrm{mM})$. The noise prior to 100 seconds for each curve is a result of opening the Faraday Cage to inject glucose into solution. All transients were recorded under nitrogen gas. 


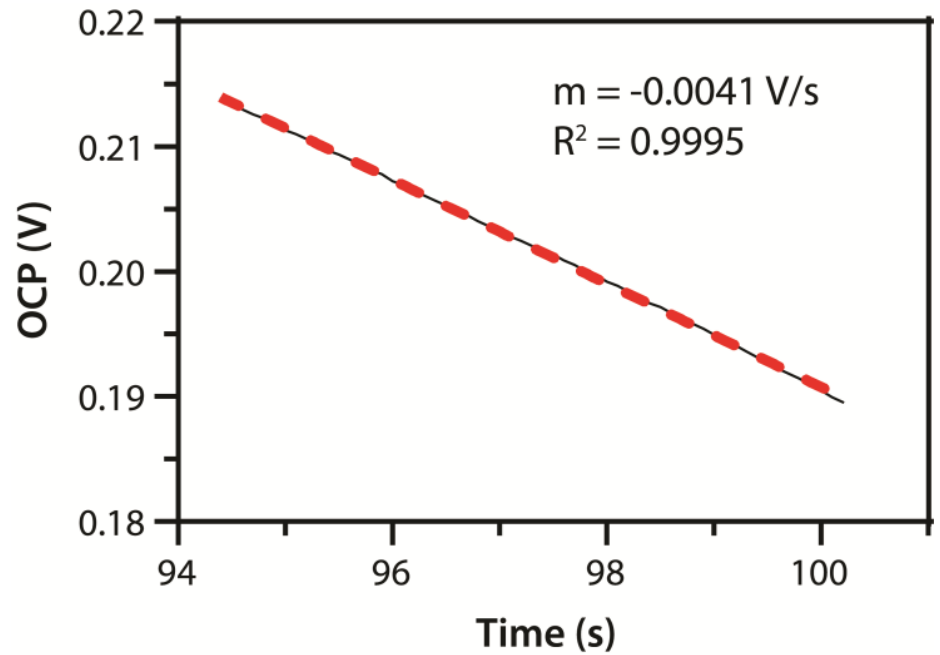

Fig S4. Linear Region from a Potential Transient for $100 \mathrm{mM}$ Glucose 


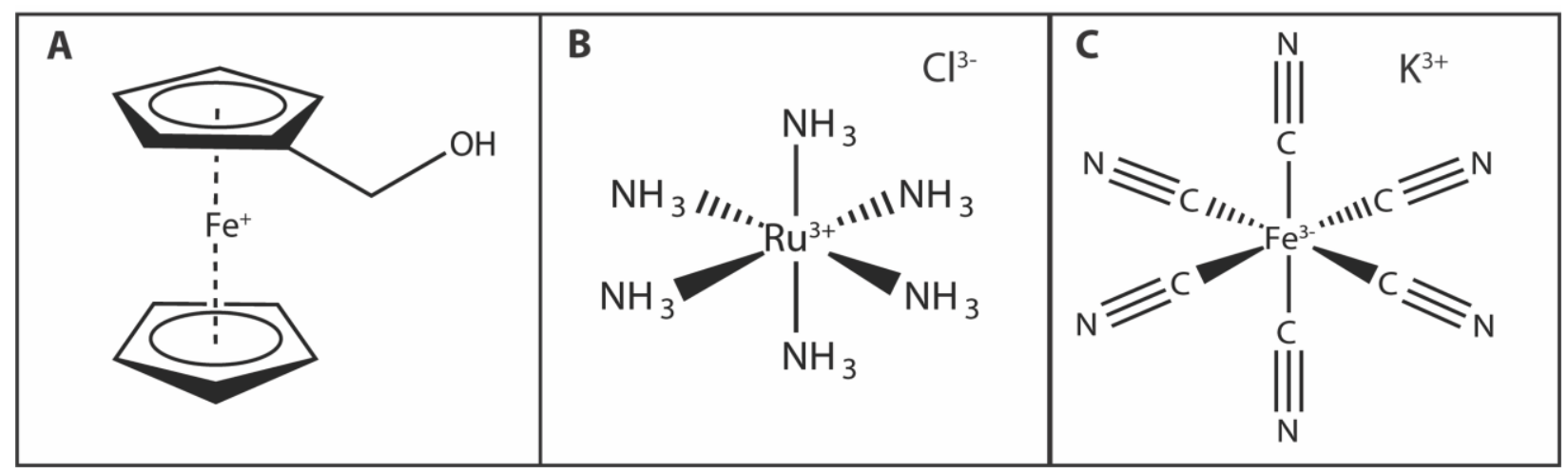

Fig S5. Mediator Structures (A) Ferrocenium Methanol. (B) Hexaammineruthenium(III) chloride. (C) Ferricyanide. All structures were drawn using chemdraw. 


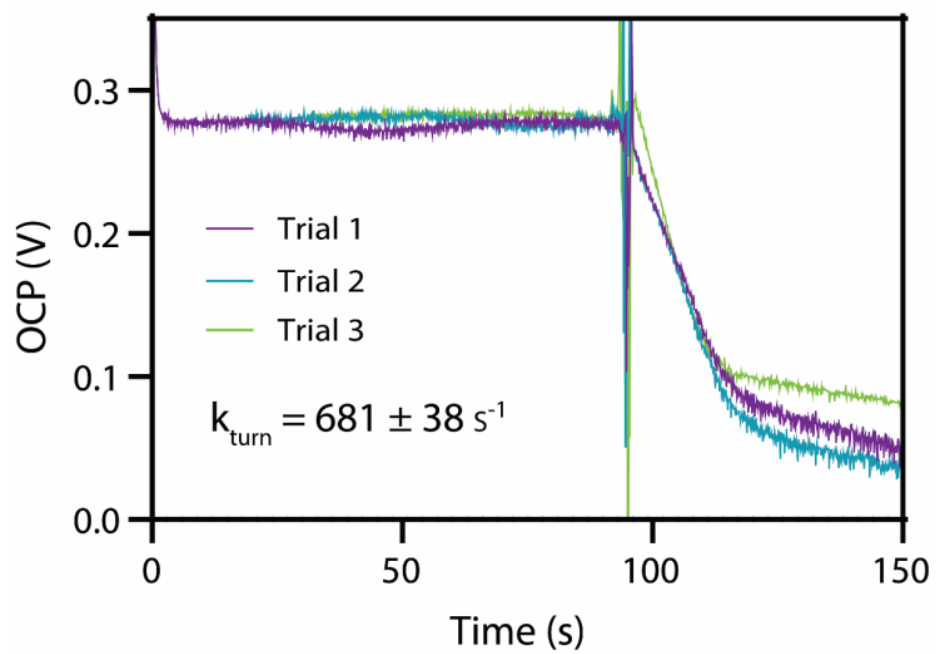

Fig S6. Potential Transients under Air for 75 mM Glucose. Solutions were not purged under nitrogen prior to experimentation nor were they kept under nitrogen while potentiometric measurements were taken. A Pt microelectrode $(r=5 \mu \mathrm{m})$ and a $\mathrm{Ag} / \mathrm{AgCl}$ reference electrode with a salt bridge were used. 